Saudi Journal of Biomedical Research

Abbreviated Key Title: Saudi J Biomed Res ISSN 2518-3214 (Print) IISSN 2518-3222 (Online)

Scholars Middle East Publishers, Dubai, United Arab Emirates Journal homepage: https://saudijournals.com/sjbr

Original Research Article

\title{
Is it Possible to Cure COVID-19 Patients with Minocycline and Platelets Transfusion?
}

Mosab Nouraldein Mohammed Hamad*

Research Unit, Banoon Fertility Center, Sudan

DOI: 10.36348/sjbr.2020.v05i04.004 | Received: 07.04.2020 | Accepted: 16.04.2020 | Published: 24.04 .2020

*Corresponding author: Mosab Nouraldein Mohammed Hamad

\section{Abstract}

COVID-19 is a universal disaster that affects the global health, economy, and restricts population movements. In this study we suggest that minocycline; second generation of tetracycline antibiotic with platelets transfusion may cure COVID-19 patients. As we have no facilities and even no positively confirmed patients in Sudan, so we send my suggestions to save my brothers and sisters in humanity worldwide, and I hope that god bless my suggestions and gain fruitful results.

Keywords: COVID-19, treatment, Platelets, Tetracyclines, Minocycline.

Copyright @ 2020: This is an open-access article distributed under the terms of the Creative Commons Attribution license which permits unrestricted use, distribution, and reproduction in any medium for non-commercial use (NonCommercial, or CC-BY-NC) provided the original author and source are credited.

\section{BACKGROUND}

Coronaviruses are a huge family unit of viruses that lead to sickness range from mild to more harsh sicknesses. Coronavirus disease (COVOID-19) is a novel strain that was discovered in 2019 and has not been before recognized in humans. It's a zoonotic illness.

Frequent signs of infection comprise respiratory symptoms, fever, and cough, shortness of breath and breathing problems. In more stern states, infection can lead to pneumonia, severe acute respiratory syndrome, renal failure and even loss of life [1].

Platelets are a chief constituent binding between the steps of hemostasis, inflammation, and tissue repair. In seconds, they react to specific signals produced on tissue injury or attack by pathogens. On stimulation, it recently expresses receptors for adhesive proteins, and they aggregate and discharge a plethora of cytokines and other mediators. Furthermore, activated platelets create direct contact with endothelial cells, granulocytes, monocytes, and lymphocytes. By these contacts, they may either stimulate or slow down roles of the other cellular partners in inflammation, and it supports the trans-endothelial migration of leukocytes into adjacent tissue [2].

Viral infection of a vulnerable cell begins with virus linking to a surface receptor that mediates its internalization through the endocytic pathway. Fruitful infectivity relies on the capability of the virus to flee endosomal acidification and lysosomal fusion throughout varied methods, transporting its genome to the cytoplasm or nucleus depending on the virus type. The major methods for platelet communication with viruses and the PRR concerned in viral credit by platelets known so far are discussed in Figure-1. 


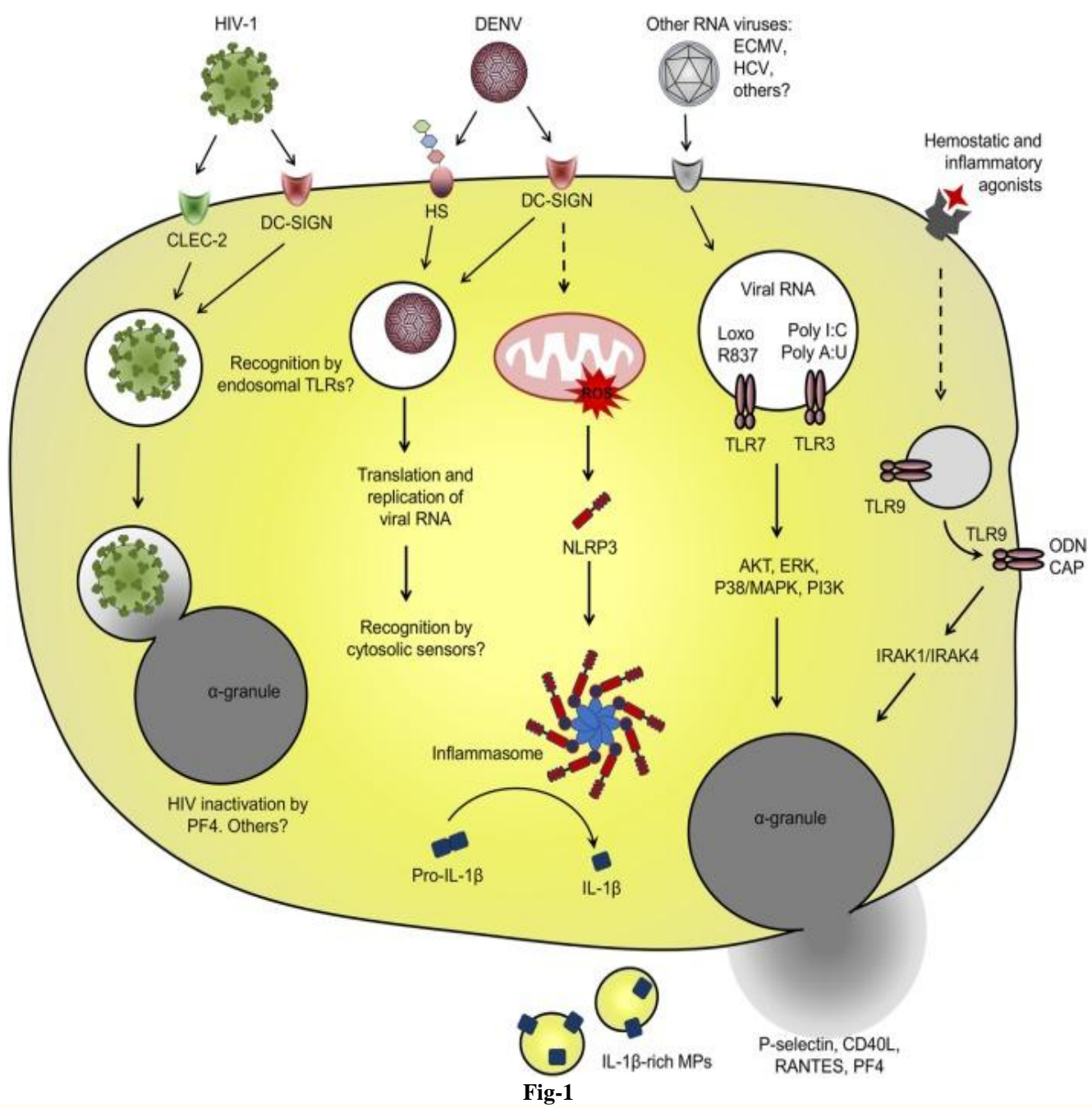

Thrombocytes interface with viruses and virusrelated pathogen-associated molecular patterns (PAMPs): diagram symbol of the major receptors and pathways concerned in virus connecting and internalization, and pattern recognition receptor concerned in credit of viral PAMP by platelets [3].

Tetracyclines are bacteriostatic antimicrobial agent, active against a broad spectrum of bacteria, Rickettsia, Chlamydia, Mycoplasma, Plasmodium, Spirochetes and Mycobacteria. The method of act of tetracycline consists of their capability to link to bacterial 30s ribosomal subunit and suppress protein production.

Minocycline is a second-generation semisynthetic tetracycline. The medicine has improved pharmacokinetic profile than the first-generation tetracyclines; it is totally absorbed when taken in its oral formulation and is approximately entirely bioavailable. The drug is extremely lipophilic and passes without difficulty through the blood-brain barrier and has been shown to build up both in the CSF and CNS cells. The remedy has good safety evidence and is well tolerated in human beings even when used chronically. The most frequent side effects comprise nausea, vertigo, mild dizziness which are totally reversible upon discontinuation of the remedy. Other side influences comprise liver toxicity, pigmentation and a lupuserythematosus-like syndrome.

It exerts characters such as anti-inflammatory, anti-apoptosis and immune modulatory activity, and was shown to have neuroprotective effects. CD40/40L pathway regulates numerous inflammatory mechanisms. Minocycline down-regulates CD40L on T cells, thus exerting anti-inflammatory influences. These characters are self-governing of its antimicrobial activity. The non-antimicrobial characters explained have also been attributed from minocycline's capacity to suppress the action of major enzymes such as caspase- 1 and -3 , and improvement of BcL-2.

Antagonistic action of minocycline against viruses has been originally described against HIV and afterward was evaluated in a diversity of trial infections with different viruses [4]. Minocycline was predicted to overturn H7N9 viral replication by computational processes. Drewes et al., reported that Minocycline attenuated in vitro induction of type I interferon cells and interferon enthused genes in PBMC exposed to both HIV and influenza virus. 
The Covid-19 pandemic is a case in position. We want to save lives now as also improving the way we react to outbreaks in common. The initial point is more urgent, but the next has critical long-term penalty. The long-term confront - improving our capability to react to outbreaks - isn't new. International health experts have been saying for years that one more pandemic whose pace and sternness rivaled those of the 1918 influenza epidemic was a subject not of if but of when. ${ }^{1}$ The Bill and Melinda Gates Foundation has dedicated considerable resources in current years to serving the world get ready for such a scenario.

Currently we also face an instant crisis. Covid19 has continuing performing a lot like the once-in-acentury pathogen we've been anxious about. I hope it's not that awful, but we should suppose it will be until we know otherwise.

There are two causes that Covid-19 is such a danger. Primary, it can kill fit adults in addition to elderly people with presented health problems. The information so far propose that the virus has a case fatality risk around $1 \%$. Second, Covid-19 is transmitted quite competently. The average infected human being spreads the illness to two or three others - an exponential rate of augment. There is also strong proof that it can be transmitted by public who are just mildly sick or even pre-symptomatic. That indicate Covid-19 will be much harder to hold than the Middle East respiratory syndrome or severe acute respiratory syndrome (SARS), which were extend much less efficiently and only by symptomatic people. In fact, Covid-19 has previously caused 10 times as several cases as SARS in a quarter of the time.

We aimed to suggest that minocycline with platelets transfusion may treat persons infected with COVID-19.

\section{METHOD}

Patients: COVID-19 confirmed patients.

\section{Patient Management \\ Platelets Transfusion}

The choice to transfuse platelets relies upon the clinical state of the patient, the cause of thrombocytopenia, the platelet count and the functional aptitude of patients' platelets. A platelet concentrate containing about $0.7 \times 10^{11}$ platelets should cause a platelet count raise of 5000 to $10,000 / \mu \mathrm{l}$ in an average sized adult. The majority institutions have adopted plans for a standard platelet dose of so several units of pooled platelets. Ordinary local practices have incorporated 4,6 or 8 to 10 units as their "dose" for adults. Though, more hospitals are altering guidelines to more suitably treat patients of dissimilar sizes and weights. They have adopted guidelines to provide one platelet concentrate per $10 \mathrm{~kg}$ of body weight. This should raise the platelet count by about $40,000 / \mu \mathrm{l}$. It is value mentioning here that when transfusing platelets no other rehabilitation should be given in another IV line. Such treatments contain antibiotics or other biochemical agents that may suppress platelet function and make the transfusion ineffective [5].

\section{MINOCYCLINE DOSAGE}

For adults: $200 \mathrm{mg}$ orally at first followed by $100 \mathrm{mg}$ orally every 12 hours.

For Pediatrics: Older than 8 years: $4 \mathrm{mg} / \mathrm{kg}$ orally or IV at first followed by $2 \mathrm{mg} / \mathrm{kg}$ orally or IV every 12 hours. Utmost dose: $200 \mathrm{mg} /$ dose at first followed by $200 \mathrm{mg} /$ day [6]. Less than 8 years $1 \mathrm{mg} / \mathrm{kg}$ [7].

\section{RESULT}

We suggest that minocycline with platelets transfusion my resolve COVID-19 crisis.

\section{CONCLUSION}

Our study is just opinion article aimed to support the efforts excreted by scientific community to defeat COVID-19.

\section{RECOMMENDATIONS}

Platelets transfusion and then drug (minocycline) administration must be done after laboratory confirmations of this strategy as treatment for COVID-19 patients.

\section{REFERENCES}

1. World Health Organization, health topics, Coronavirus, topics/coronavirus. https://www.who.int/health-

2. Klinger, M. H., \& Jelkmann, W. (2002). Role of blood platelets in infection and inflammation. Journal of interferon \& cytokine research, 22(9), 913-922.

3. Hottz, E. D., Bozza, F. A., \& Bozza, P. T. (2018). Platelets in immune response to virus and immunopathology of viral infections. Frontiers in medicine, 5, 121.

4. Nagarakanti, S., \& Bishburg, E. (2016). Is minocycline an antiviral agent? A review of current literature. Basic \& clinical pharmacology \& toxicology, 118(1), 4-8.

5. Mohanty, D. (2009). Current concepts in platelet transfusion. Asian journal of transfusion science, 3(1), 18-21.

6. Minocycline Dosage. https://www.drugs.com/dosage/minocycline.html.

7. https://reference.medscape.com/drug/dynacinminocin-minocycline-342549. 